\title{
Effect of N-Substituent on the Protein-Binding of Carcinogenic Aminoazo Dyes
}

It has been shown that hepatocarcinogenic $4-\mathrm{N}$-dimethylaminoazobenzene (DAB) is firmly bound to the proteins of the target organ, and that the dye-protein thus formed is hydrolyzed with alkali or protease to the amino acid or oligo peptide linked to an aminoazo dye moiety. ${ }^{1)}$ This fragment is named "bound dye" or " polar dye." Other carcinogenic aminoazo dyes which have at least one N-methyl group; i.e., 4-N-methylaminoazobenzene (MAB) or 4-N-methyl-N-ethylaminoazobenzene (MEAB), are also able to form the bound dye. The $\mathrm{N}$-methyl group of those dyes is in general metabolized rapidly to formaldehyde. However, in the bound dye prepared from $4-\mathrm{N}-{ }^{14} \mathrm{C}-$ methyl$\mathrm{MAB}$, the radioactivity was reserved almost quantitatively. ${ }^{2,3}$ This finding suggests that $\mathrm{N}$-methyl group may contribute to the binding between the protein and the dye.

The communication presented here is concerned with problem whether the bound dyes prepared from the livers of rats administered MAB or 4-N-methyl-N-alkylaminoazobezoene have different physico-chemical properties due to the N-substituent or entirely the same property. In a recent paper, it was shown that the rate of $\mathrm{N}$-demethylation was greatly influenced by the presence of another $\mathrm{N}$-substituent. ${ }^{4}$. As for 4-N-methyl-Nisopropylaminoazobenzene (MPAB), the reaction in the first step is the splitting off of the $\mathrm{N}$-methyl group, although $\mathrm{N}$-deisopropylation is partly observed, and the rate of $\mathrm{N}$ demethylation is remarkably faster than that of MAB. MPAB was bound to the liver proteins, while its first oxidation product, $4-\mathrm{N}$-isopropylaminoazobenzene (PAB), was hardly able to form the bound dye. Therefore, the binding might be performed by the chemical interaction between MPAB and the liver proteins, probably during the course of N-demethylation. Then, the primarily formed bound dye, if stable, may have the $\mathrm{N}$-isopropyl group, and show characteristic properties due to the N-substiuent.

The crude bound dye was prepared from the hydrolysate of the defatted powder of the livers of rats which had been fed the aminoazo dye. The procedure in detail will be presented in a coming paper. The bound dye was applied to the chromatographic separation on an ion-exchanger column (Amberlite $\mathrm{CG}-50, \mathrm{H}^{+}$form). ${ }^{5}$ ) Each bound dye prepared from different dyes, MPAB and MAB, showed a similar chromatographic pattern, which displayed two main peaks, designated $A$ and $B$, respectively. The components, $\mathrm{A}$ and $\mathrm{B}$, were fractionated further by ascending paper-chromatography with the following solvent system; aqueous layer of $n$-propanol, $n$-butanol and water, 1:4:5. Component $B$ was separated into two sub-components, $B_{1}$ and $B_{2}$. Those three components, $A, B_{1}$ and $B_{2}$, were rechromatographed carefully on the filter paper (ToyoRoshi No. 51A). The thoroughly purified dyes were applied to the spectrophotometric measurement. The physico-chemical properties were shown in Table I. The corresponding components of the bound dye prepared from these two aminoazo dyes appeared to show the same properties.

The purified component $B_{2}$, when it was rechromatographed on the filter paper, was separated clearly into two spots. The dye which travelled slowly was $B_{2}$ itself, and another dye $B_{2 \beta}$ showed the same $R f$ as $A$. In component $B_{1}$, a slight discrepancy

1) J.A. Miller, E.C. Miller : in “Advances in Cancer Research,” Vol. 1, p. 340 (1953), edited by J. P. Greenstein, A. Haddow, Academic Press, New York.

2) H. Terayama, M. Ishidate, A. Hanaki : Nature, 184, 1460 (1959).

3) T. Higashinakagawa, M. Matsumoto, H. Terayama : Biochem. Biophys. Res. Commun., 24, 811 (1966).

4) A. Hanaki : Biochim. Biophys. Acta, 63, 215 (1962).

5) A. Hanaki, H. Terayama: Gann, 53, 285 (1962). 
TABLE I. Physico-chemical Properties of the Bound-Dye

\begin{tabular}{|c|c|c|c|c|c|c|c|}
\hline \multirow{2}{*}{ Component } & \multirow{2}{*}{$\begin{array}{c}\text { Dye } \\
\text { administered }\end{array}$} & \multirow[b]{2}{*}{$\mathrm{pKa}$} & \multirow[b]{2}{*}{ Rf } & \multicolumn{4}{|c|}{$\begin{array}{l}\text { Characteristic band in electronic } \\
\text { absorption spectrum }(\mathrm{m} \mu)\end{array}$} \\
\hline & & & & $\begin{array}{l}\text { Q-Band in } \\
4 N \mathrm{HCl}\end{array}$ & $\begin{array}{l}\mathrm{K}-\mathrm{Band} \text { at } \\
\mathrm{pH} 4.5\end{array}$ & $\begin{array}{l}\text { Isosbestic } \\
\text { point }\end{array}$ & $\begin{array}{l}\text { K-Band in } \\
\text { Ethanol }\end{array}$ \\
\hline $\mathrm{A}$ & MAB & 0.80 & 0.48 & 516 & 395 & 450 & 392 \\
\hline $\mathrm{A}$ & MPAB & 0.80 & 0.48 & 515 & 394 & 448 & 391 \\
\hline $\mathrm{B}_{1}$ & MAB & 2.8 & 0.62 & 518 & 402 & 460 & 402 \\
\hline $\mathrm{B}_{1}$ & MPAB & 2.6 & 0.61 & 520 & 402 & 460 & 400 \\
\hline $\mathrm{B}_{2}$ & MAB & 2.00 & 0.36 & 520 & $405 \sim 410$ & 459 & 400 \\
\hline $\mathrm{B}_{2}$ & MPAB & 1.95 & 0.36 & 520 & $405 \sim 410$ & 457 & 400 \\
\hline $\mathrm{B}_{2 \beta}$ & MAB & 0.75 & 0.48 & 515 & 394 & 448 & 391 \\
\hline $\mathrm{B}_{2 \beta}$ & MPAB & 0.75 & 0.49 & 515 & 394 & 448 & 390 \\
\hline
\end{tabular}

Components $B_{1}$ and $B_{2}$ were measured at ionic strength 0.1 , and components $A$ and $B_{2} \beta$ at 1.0 .

in pKa was observed between the bound dyes prepared from the different dyes. This might be attributed to some impurities contained in $B_{1}$. Component $B_{1}$ appeared to be transformed very slowly to another dye which might have lower $\mathrm{pKa}$ and higher $\mathrm{Rf}$ than $B_{1}$, and those two components were not separated clearly; but $B_{1}$ was remarkably stable as compared with $B_{2}$. Those findings support that components $B_{1}$ and $B_{2}$ derived from MPAB have lost already the $\mathrm{N}$-isopropyl group and have the same structures as the corresponding components from MAB. The expected component which would support the presence of $\mathrm{N}$-isopropyl group could not be isolated as a main component. This fact is of particular interest, because it is suggested that the dye-protein binding might be achieved at the $\mathrm{N}$-methyl position, where a strong steric interference would be anticipated between $\mathrm{N}$-isopropyl group and the amino acid residue of the protein linked to the dye. Since the amino acid moiety is sterically larger than $\mathrm{N}$-isopropyl, the formation of this metastabie product might enhance the splitting-off of the $\mathrm{N}$-isopropyl group.

When the bound dye was stored for a few months or treated with dilute alkali, the slight amount of the non-polar dyes, which were identified as MAB as well as 4-aminoazobenzene $(\mathrm{AB})$, were liberated. In general, $\mathrm{MAB}$ is never detected in the metabolites

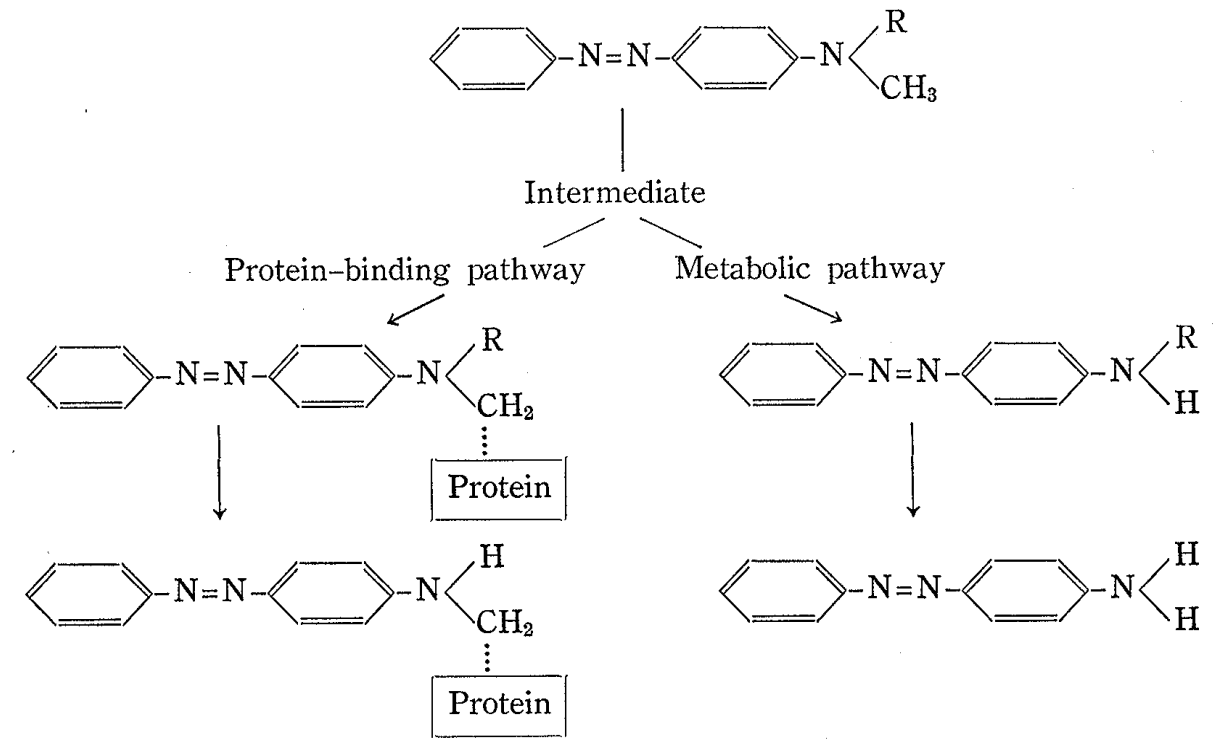

Fig. 1. A Proposed Schema for the Protein-Binding and Metabolic Pathways of 4-N-Methyl-N-alkylaminoazobenzene 
of MPAB; because the rate of $\mathrm{N}$-demethylation in this dye is greatly faster than that of $\mathrm{N}$-deisopropylation. ${ }^{4}$ Certainly, the azo-metabolites detected in bile and in urine were $\mathrm{PAB}$ and $\mathrm{AB}$, and the product of $\mathrm{N}$-dealkylation catalyzed by rat-liver homogenate was PAB. Therefore, a possibility may be considered that MAB is liberated undoubtedly from the bound dye, and the binding between the dye and the protein involves $-\mathrm{N}-$ $\mathrm{CH}_{2} \cdots$ group.

$A$ significant difference between component $B_{1}$ and $B_{2}$ is the mobility on the paper chromatogram. $B_{1}$ was more hydrophilic, and $B_{2}$ relatively lipophilic and sparingly soluble in benzene. This phenomenon might be ascribed to the difference between the properties, especially solubility, of the amino acid or peptide attached to the dye fragment. Another difference is observed in $\mathrm{pKa}$, which is derived from the proton associating ability of the aminoazo dye part. On the other hand, the spectral characteristics are closely resembled. Since the characteristics of the electronic absorption spectrum generally reflect the structure of the chromophore, those facts support that the structure of aminoazo dye fragment invloving the dye-protein linkage would be similar in each component of the bound dye, and the difference would be expected in the structure of the amino acid residue attached to the dye. A proposed schema for the protein-binding and metabolic pathways presented in Fig. 1. A complete account of the present communication will be reported in near future.

National Institute of Radiological Sciences, Chiba

Akira Hanaki (花木 嘫)

Received February 21, 1967 